\title{
Social Media Sites Enhance Online Teaching and Learning Activities: Instructors’ Perceptions: A Case Study
}

\author{
Dan V. Dao \\ Texas Tech University, Lubbock, U.S.A
}

\begin{abstract}
Online teaching and learning environments have been booming worldwide. However, many universities in developing countries cannot afford learning management systems, such as Blackboard or WebCT. Therefore, this qualitative study explores the possibility of using social media sites for online instruction due to the fact that their prominent utilities are similar to those of Blackboard and other learning management systems. Through purposeful sampling, four university professors using social media for online instruction were selected as participants, in order to gain insights from their perspectives regarding its usage as an alternative instructional medium. Using the constant comparison method and open coding, data was gathered and triangulated from participant interviews, observations of participants' online courses on social media sites; documents collected from their online courses; and the researcher's reflexive journal. Thematic findings revealed that social media sites increased (1) interaction and communication between the instructor and students, (2) interaction, communication, and collaboration among students, (3) and interaction between students with materials. It is believed that the significance of the research findings can be transferred to the similar online teaching contexts where learning management systems cannot be afforded.
\end{abstract}

Keywords: social media sites, online, qualitative, technology

\section{Introduction}

Technology has many prominent features, and it is increasingly exploited in education. Specifically, computers and the Internet have had a great impact on the use of technology in education. Online education is becoming more and more common in many schools and universities nowadays because of the advantages of the Internet. Officially, one of the most popular learning management systems is Blackboard. Blackboard was founded in 1997 by two educational advisors, Matthew Pittinsky and Michael Chasen. Blackboard is used by more than $70 \%$ of universities and colleges in the U.S. (Bradford, Porciello, Balkon, \& Backus, 2007). In June 2006, "the Blackboard empire included over 12 million users in over 60 countries. Products are offered in 12 languages to over 2,200 learning institutions and contain more than 2,500 supplements from educational publishers” (Bradford, Porciello, Balkon, \& Backus, 2007, p. 2). These statistics mean that Blackboard is a very powerful learning management system in education.

According to the authors, Blackboard brings instructors and learners many benefits, such as increased availability (e.g., the teacher and students can access the course via Blackboard at anytime and anywhere), quick feedback (e.g., students can see the quiz results right after they submit their tasks), improved

Dan V. Dao, Ph.D., Texas Tech University. 
communication (e.g., via email box, announcement tool, or chat functions), tracking (e.g., keeping records of students' access, like the time and the date of students' access), and skill building (e.g., time management) (Bradford, Porciello, Balkon, \& Backus, 2007). The Blackboard learning system has content management and content sharing, assessment management tool, grade-book function, discussion board (collaboration and communication), assignment and portfolio management threads. Therefore, Blackboard is not only very good for designing an online course, but also a very suitable tool for supplementing a face-to-face course.

Although the Blackboard learning system has many prominent features for teaching and learning activities, many universities cannot afford the system. One reason is the high cost of the learning management system. According to Bradford, Porciello, Balkon, and Backus (2007), "Subscription licenses may be $\$ 200,000$ to \$400,000-a-year” (p. 5). This price makes Blackboard unaffordable by many schools and universities in developing countries. Another reason that many universities do not use Blackboard is that Blackboard is hard for teachers as well as for students to use. Bradford, Porciello, Balkon, and Backus (2007) made a survey of 730 faculty, staff, and students in the University of Wisconsin System. The results showed that the majority of the survey participants reported that the Blackboard learning management system is "harder to learn to use than expected” (Bradford, Porciello, Balkon, \& Backus, 2007, p. 4). This technical skill may also cause trouble for teachers and students in developing countries. This research interest is to study prominent features of social media sites for teaching and learning activities that can be effectively applied for the learning environment where other learning management systems, like Blackboard or WebCT are not affordable.

The primary purpose of this study was to examine the perceptions of professors at Texas Tech University (TTU) and at other universities who have applied social media sites to their online teaching. This research question guided my study:

What are the perceptions of professors at TTU and other universities concerning their use of social media sites in their online course instruction?

I believe that the research findings will be very beneficial for the instructors and students who want to apply social media sites to their teaching and learning activities and who want to incorporate social media sites with other learning management systems in their online teaching.

\section{Literature Review}

Along with the rapid and prominent development of the Internet, Blackboard, the learning management system for most online courses emerged in 1997 (Sylvester, 2011). Blackboard is a web based course management system that allows instructors to integrate the use of technology within their classrooms. The advantages of Blackboard are enhancing peer communications, teacher-student communications, a variation in learning styles, and sources of course information. Within Blackboard, students have access to discussion boards, chat software, and email. Teachers also have the option of posting announcements that are accessible to anyone enrolled in Blackboard (Blackboard Inc., 1997).

Unfortunately, many universities in developing countries such as Vietnam, Cambodia, the Philippines, and others cannot afford course management systems such as Blackboard or WebCT. In an effort to provide these countries with the benefits offered by technological instruction, I will research how social media sites can provide instructors and students with many of the features of proprietary course management systems.

What is a social media site? Kaplan and Haenlein (2010) defined social media as "a group of 
Internet-based applications that build on the ideological and technological foundations of Web $2.0{ }^{1}{ }^{1}$ which allows the creation and exchange of user-generated content”" (p. 61).

Researchers have found that prominent features of social media sites can be effectively used in online teaching and learning activities for these benefits: Social media sites are advantageous to teaching and learning; they positively change the roles of the teachers and students in the classroom; they are excellent for discussion across classes; and they are easy to use and are free of charge.

\section{Social Media Sites are Advantageous to Teaching and Learning}

Regarding prominent features of social media sites, researchers like Campbell (2003), Cheon, Song, Jones, and Nam (2011), Ellison and Wu (2008), Sawmiller (2010), Soares (2008), and Yang (2009), as well as others, have done studies on advantages of applying social media sites, especially blogs (e.g., Blogger.com, Wordpress.com, PBworks.com, Groups.yahoo.com, or Facebook.com) to teaching and learning activities. All of these researchers found that using social media sites is very good for teaching and learning activities.

Specifically, according to Campbell (2003), there are three types of blogs "that fit pedagogical purposes: the tutor blog, run by the class teacher; the learner blog, run by each student in the group individually; and the class blog, run by teacher and students collaboratively" (p. 518). The class blog is a joint effort between teacher and students. This kind of blog is used as a collaborative discussion board and an extra-curricular extension of the classroom (Soares, 2008). The advantages of teaching and learning with blogs are promoting student-centered learning activities, increasing creativity of students during problem solving, enhancing interaction between the teacher and students and among students for building collaborative knowledge, and creating a rich, engaging, and exciting learning environment (Cheon, Song, Jones, \& Nam, 2011). Since the classroom blogs promote student-centered learning, students invest more time and energy in their studying and discussion without the fear or shame that they may have in face-to-face classes. They are always aware that they are writing and posting something for an internet audience, their teacher, and their peers. As a result, they improve their learning, especially their reading and writing skills (Ellison \& Wu, 2008).

Similarly, in his research, Sawmiller (2010) discovered "using a blog in the classroom can also increase motivation, challenge critical thinking, aid in differentiated instruction, and extend the classroom wall” (p. 44). In fact, using blogs for discussion gives students more time to read their peers' answers and think of their own answers to the discussion questions in order to effectively contribute to their class discussion. The more they are aware of their learning autonomy, the more they improve and gain knowledge.

Yang (2009) agreed on the advantages of using classroom blogs for teaching and learning activities and said "blogs allow people to exchange information without space and time constraints, to broaden their knowledge, and to meet personal needs and interests at the same time” (p. 13). Yang also implied that classroom blogs allow the instructor to upload document files, PowerPoint presentation files, audio and video files, pictures, slideshows, and discussion questions on the discussion board and send instant offline messages in many cases. On the other hand, students can download the files, get up-to-date information from the instant messages, and contribute to the class discussion questions on the class board. Also, students can use the classroom blog to journal their thoughts and experiences on a special topic or in a project. Each student can contribute entries, and the instructor can follow along. All the above facts lead to the reality that students can

\footnotetext{
${ }^{1}$ Retrieved from http://en.wikipedia.org/wiki/Web_2.0

2 Retrieved from http://en.wikipedia.org/wiki/User-generated_content
} 
maximize their learning opportunities.

In general, social media sites are very good for teaching and learning activities, and they bring benefits for both the teacher and students in the interactive and communicative learning environment.

\section{Social Media Sites Positively Change the Roles of the Teachers and Students in the Classroom}

The teacher plays an important role in students' learning styles. According to Chang and Fisher (2003), the teacher role in any mode of teaching, either in face-to-face classes or online classes, is to "ensure that some type of educational process occurs amongst the learners involved” (p. 5). Researchers, such as Goodyear, Salmon, Spector, Steeples, and Tickner (2001), Wang (2006), Ellison and Wu (2008), and others conducted research on how technology positively changes the roles of teachers and students in online classrooms. They found that technology and students' empowerment in choosing project topics and technology for their project play important roles in changing the teacher-student roles in class.

Goodyear, Salmon, Spector, Steeples, and Tickner (2001), who reported the ideas on online teacher roles from practitioners and researchers attending the two day workshop, pointed out eight roles for online teachers. They reported that the online teacher should be a content facilitator, technologist, designer, manager/administrator, process facilitator, adviser/counselor, assessor, and researcher. Although the teacher roles found in their workshop were different in names, their tasks were almost the same: taking care of postings on the class discussion platforms (forums), encouraging participation, keeping the learning process on pace, encouraging and motivating students, and keeping the discussion focused and effective. The teacher roles in online classes allowed the students to control and manage their study pace and motivate students' learning autonomy much more.

Wang (2006) conducted an action research study at a university on a U.S. border in the Western Pacific region. The students joining in the research were the ones taking an educational computing course. The purpose of the research was to find out how the students applied computer applications to different educational contexts. The students were free to choose the topic and multimedia tools for their project. After analyzing data from the student projects, field notes, and interviews, Wang found that "technology serves as a vehicle for students to share their personal and collective experiences” (2006, p. 322). The students used different multimedia, such as videos, conferencing videos, audios, photos, and text to communicate with each other to finish their projects. She also emphasized "computers provided students with an ideal forum to show their talents” (Wang, 2006, p. 323).

Also, in their research with 68 undergraduate students on student perceptions of blogging in the classroom, Ellison and $\mathrm{Wu}$ (2008) found that students enjoyed the online writing assignments through different interactions, through the exposure to the different ideas of their peers on the topic, and the access to a wide online audience. Blogging encouraged them to write something in a "more authentic voice" (Ellison \& Wu, 2008, p. 116). One of the students in the research acknowledged "writing on a blog page is better than writing a standard essay type, hand-in paper” (Ellison \& Wu, 2008, p. 112).

To sum up, online classes designed from different online interactive modes, such as online resources and blog discussion boards, positively motivate students' learning. Students have many opportunities to show their interests and engagement through their work. The roles of teachers and students in classes have been changed from the teacher-centered approach to the student-oriented approach.

\section{Social Media Sites are Excellent for Discussion Across Classes}

Blogging across the curriculum is one of the prominent features of blogging, one type of social media sites. 
Richardson (2010) indicated one point for educators and students when using blogs for teaching and learning activities. He said that instructors can benefit from blogs in all areas of the curriculum. They can share and discuss topics with experts and friends; they can share results of surveys, research, or experiments with experts and colleagues; they can publish students' projects, including their outstanding blog work. For students, Richardson specifically pointed out that his students can work or collaborate with peers from other classes on the same math problems. This means that students attending math in one class with a specific teacher can share ideas and ask for help from other students from different classes. This function of blogging is obviously useful for both instructors and students in online teaching and learning activities. Richardson illustrated this prominent feature of blogging by providing an example from Mr. C.’s class blog (tinyurl.com/clby52).The teacher writes in his blog:

I wanted to share my classroom with people outside of my classroom. I wanted my students to show what they were doing to anyone that wanted to see, [and] I wanted a connection to form between my students and the world. (Mr. C.'s class blog, p. 35)

Similarly, according to Ventureneer (2011), social media is not one person’s job. It indicates:

Social media produce the best results when used across all departments of an organization. Every department or program can and should be involved in posing and answering questions for online groups; providing material for blogs; connections on LinkedIn and Facebook; and responding to comments or queries received via social media. (p. 9)

In short, this function of blogging allows the instructor to connect into one group the students from different classes who have the same majors or subjects. They have a good opportunity to ask, share, and discuss on the topic.

\section{Social Media Sites are Easy to Use, Easily Available, and Inexpensive}

Social media sites are easy to use. Lankshear and Knobel (2006), Sifry (2007), Soares (2008), and Yang (2009) have conducted research on the ease of use of social media sites, and they all pointed out that using blogs is easy to set up and easy to participate in.

First, it is very easy to set up a blog. It takes less than 30 minutes for someone who wants to build a blog. For example, in the case of using Blogger.com, setting up a new blog involves a simple six-step process: register with Blogger.com by selecting a username and a password, confirm the user agreement of Blogger.com, begin building an actual blog, choose a free hosting service or use their own server space, choose an address for the new blog, and finally, choose an interface template (style or pattern) for the new blog (Lankshear \& Knobel, 2006). Additionally, it is easy to be followers of social media sites. When someone (e.g., an instructor) finishes setting up the blog, he or she then sends an email to invite the class members to join as members of the classroom blog. Since they have been invited and have joined the blog, they can post anything such as their own texts or embedded materials in order to contribute to the class discussion (Soares, 2008).

One of the most interesting things about blogging is how easy it is for bloggers to give comments and receive comments from peers and the teacher. Anyone with access to the Internet can read blog entries and leave a comment on what they have read. There are two ways to give comments. The first way is "to add the comments themselves in response to a comment” (Lankshear \& Knobel, 2006, p. 7). Another way is "to pick up on a comment made to a post and make it the subject of a subsequent post” (Lankshear \& Knobel, 2006, p. 7). It is easy for the blog members to keep track of the posts because the latest post will appear at the top of the 
wall page, and the oldest one will be at the bottom of the wall page. In addition, bloggers can also post a link that will open a new dialogue window of the blogger's desired page.

Thanks to the convenient function of blogs, the classroom members can share personal blogs or sources for class learning. In her research, Yang (2009) found that most of the participants in her research said that it is very "easy and comfortable to post comments and challenge their peers on the blog instead of discussing the issue in a face-to-face context, allowing comments to be more critical” (p. 17). The participants of the research also expressed positive attitudes toward the use of blogs as a platform to reflect their teaching and learning activities. A real benefit is that students who are shy or do not like to speak in front of others in the class have a chance to voice their thoughts in the online discussion.

Social media sites are easily accessible. Bloggers always feel that it is easy to access social media sites. Participants (e.g., students) can access the blogs to do homework and to give comments to their peers anytime and anywhere. This can be done at home, in a computer room, or at a café where the Internet is available. It is easy to get access to social media sites without any system management control and problems. The system is never down (Soares, 2008). Since blogs are easy to set up and easy to use for different purposes, especially in teaching and learning activities, according to Sifry (2007), "The number of blogs worldwide is estimated at around 70 million, with 120,000 new blogs created everyday” (p. 2).

Social media sites are inexpensive. Little research has been done concerning whether the internet users should have to pay for the cost of social media sites. According to the information presented by Hudson Horizons (2012), most social networking sites (one type of social media sites) are free, but only few require a little fee. The users do not have to pay a membership charge, and services are offered free. The Hudson Horizons also mentioned that the reason why the social media site users can get this advantage is that most social network sites are supported by paid advertisements of big companies with big budgets.

Another wonderful thing about social media sites is that they are not only free, but also there is no cost for downloading. Internet users do not have to install social media sites into their personal computers, and they do not have to pay any fees for using the sites. Also, social media sites do not require the internet users to possess any complicated technical skills. The users just create an account in ten minutes for any social media sites (e.g., Blog or Yahoo! Groups) they like and they are ready to possess a fancy and effective blog for their personal purposes (C. Lee \& A. Owen, personal communication, February 17, 2011).

In summary, researchers provided different benefits of social media sites in teaching and learning activities: Social media sites are advantageous to teaching and learning activities; social media sites positively change the teacher and student role in classroom; social media sites are excellent for discussion across classes; social media sites are easy to use and to access and are free. The researchers in the literature review also indicated that the features of social media sites are definitely excellent for teaching and learning activities, especially in the online teaching environment.

\section{Methodology}

The purpose of this research was to investigate the perceptions of professors at universities concerning their use of social media sites in their online course instruction. This research is bound in the qualitative paradigm. According to Denzin and Lincoln (1994), Lincoln and Guba (1985), Merriam (1998), and Patton (2002), qualitative research involves collecting information about personal experiences, introspection, life stories, interviews, observations, historical stories, interactions, and visual text which are significant moments 
and meaningful in people's lives. In the qualitative paradigm, the researcher is the primary instrument for data collection and analysis. This qualitative research method allows me as researcher to gain the richness and depth of data explorations and descriptions through interviews, observations, documents, and my reflexive journals.

More specifically, for this research, I employed the composite of descriptive case study technique. Merriam (1988) defines case study as "an intensive, holistic description and analysis of a single entity, phenomenon or social unit” (p. 27). According to Merriam (1988), the case can be a thing, a single entity, a unit around which there are boundaries; the researcher can "fence in" what is going to be studied. In my research, according to Merriam (1988), the case was a professor at a university experiencing social media sites in their online teaching; this is my boundary. Similarly, Yin (1984) defines case study as "an empirical inquiry which investigates a contemporary phenomenon within its real-life context when the boundaries between phenomenon and context are not clearly evident and in which multiple sources of evidence are used” (p. 23). From the definitions, a case study allows me to gather a rich and thick variety of data and provide a description of the phenomenon under study.

\section{Participants}

The selection of the participants for this research was based on purposeful sampling techniques which maximized my possibility of identifying participants who provided the best content and context regarding the phenomenon under investigation (Creswell, 2003). According to Erlandson, Harris, Skipper and Allen (1993), purposive sampling is central to naturalistic research. The main goal of purposeful sampling is to focus on particular characteristics of a population that are of interest, which will best enable the researcher to answer the research questions. This purposeful sampling strategy allowed me to maximize the two major inclusive criteria: professors teaching at a university and using social media sites in their online instruction. Four professors who were teaching online in the Spring 2013 semester were participants in my research. Three of them were teaching in different departments at the university: Educational Psychology and Leadership, Physics at Texas Tech University, and one of them was teaching in the College of Nursing at the University of Texas at Tyler.

\section{Data Sources}

Data collection is a process of gathering information from research participants. According to Merriam (1998), data collection is "about asking, watching, and reviewing" (p. 69). Data are not available out there waiting for collection, but the researcher has to select data and select the techniques of data collection. For this qualitative research, I employed four forms of data collection: (1) Interviewing, (2) conducting observations, (3) mining data from documents, (4) and compiling reflexive journals.

\section{Interviews}

I interviewed four professors who have experienced social media sites in their online teaching and I listened to their stories and experiences. All names are pseudonyms. With the professors (Prof. Lee Sung, Prof. Ken Cook, and Prof. Chris Walker) at TTU, I made appointments with them and had two direct interviews with each of them in their offices here at TTU. As for Prof. Jean Kirk in the College of Nursing at the University of Texas at Tyler, I made appointments with her and also used Skype with her. I had two interviews with her via Skype.

\section{Observation}

Observation worked well for my study. Observation was the ongoing process occurring all throughout the 
semester. I asked the professors for permission to access the online courses in Edmodo and Edu Creations in order to record systematic observation of the weekly class discussions and the interactive behaviors between the teachers and the students during the semester and also between the students themselves. I also asked Prof. Ken Cook and Prof. Chris Walker for permission to join their planned chats on Lync. Besides joining the synchronous online chats with the classes, I had all the recorded videos for the chats from Prof. Ken Cook's class. These observations were good for my data analysis process.

\section{Documents}

For my research, I collected documents from professors' online syllabuses, schedules, meeting agendas, and discussion plans; from students' online reflections and comments on the class discussion contents. All the documents were kept in separate folder going with the professor's name for data analysis process.

\section{Reflexive Journal}

I kept my reflexive journals of my experiences in teaching with social media sites. Also, since everything related to the research process was recorded in the reflexive journal, it would be one of good criteria for trustworthiness. For instance, the reflexive journals were the source for me to check time and dates of the interviews and observations, feelings, and attitudes of each respondent in each interview. Everything related to the participants, observations, or documents was recorded in the journals. Journal also recorded the research process. I really believe that the reflexive journals help contribute a convincing source to the data analysis process. Such detailed information is very important to keep readers informed about the procedures and issues of the research process.

\section{Data Analysis}

Data analysis is an ongoing process. According to Merriam (1998), the goal of the data analysis in case study "is linked to the fact that data have usually been derived from interviews, field observations, and documents” (p. 193). In order to begin the data analysis process, I first put all the data (transcripts from the interviews along with field notes during the interviews, observation notes, documents from each professor, and reflexive journals) of each professor in one folder with their name on their folder. All of this information is well-organized (Rossman \& Rallis, 2003) in a safe and convenient way so that the data can be easily retrieved later. The constant comparison analysis method was used in my informal data collection and analysis. According to Strauss and Corbin (1990), making comparisons helped the researcher in guarding bias. Through the comparisons, the researcher can achieve accuracy and consistency in the phenomena. Truly, making informal data analysis helped me see initial similarities and differences in the data to form themes for the findings in the formal data analysis process later.

Secondly, I began to look at each set of data (e.g., transcripts, observations, field notes, and documents from each of the professor) one by one in order to familiarize myself with the data. The data organization and data scrutiny were very good for me to triangulate the data sources. According to Erlandson et al., (1993), by triangulating the data, "the researcher seeks out several different types of sources that can provide insights about the same events or relationships” (p. 115). Triangulation enhanced meaning through different data sources and provided me with thick description of related information from data sources.

Next, I began to code the data. According to Emerson, Fretz and Shaw (1995), "A code is a word or short phrase that captures and signals what is going on in a piece of data in a way that links it to some more general analysis issue" (p. 146). I coded the data by the interviewees' initials, dates of each interview, the interview 
numbers, the interview transcript lines, the page numbers of each interview, and the page numbers of the field notes. Coding helped me to access the data as part of the audit trail.

After that, I unitized the data. Lincoln and Guba (1985) define unitizing data as disaggregating data into "single pieces of information that stand by themselves, that is, that are interpretable in the absence of any additional information" (p. 203). The unit of data should be short, and it serves as a semiotics to the analysis (Pennartz, 1989). Unitization of the data was done by dividing the transcribed interviews into independent units of meaning that were numbered and compiled in one file. Each unit was coded to present the participant, the date of interview, original data source (the transcripts of the interviews with the participants).These units of meaning would be used in presenting the participants' ideas in the finding chapter. Following was an example of a coded unit shown in Table 1.

Table 1

Representative Data Card

\begin{tabular}{lllll}
\hline Ref. \# & Participant & Interview/Document & Date & Source \\
\hline$[1]$ & 1. Lee Sung & Interview \# 1 & 4/15/2013 & 193-198, p. 5 \\
\hline
\end{tabular}

The final process in the data analysis process is to search for themes and to establish categories. Categories, according to Merriam (1998) are "abstractions derived from the data, not the data themselves” (p. 181). Rossman and Rallis (2003) indicate, “Categories provide direction for data gathering” (p. 282). In the process of analyzing data, responses from the professors were grouped into categories that would detail the themes. Rossman and Rallis (2003) consider theme as a phrase or a sentence that describes subtle processes. Themes often emerge during the intensive analysis process. In the process of analyzing the data for this research, I identified three main themes that would be reported in the Findings section. The themes supported the research question.

\section{Findings}

The primary purpose of this study was to examine the perceptions of professors at Texas Tech University (TTU) and other universities who have applied social media sites to their online teaching. This part of the study provides the participants experiences in using social media sites in their online teaching during the Spring 2013 semester. Their points of view have been constructed from multiple data sources: interviews, observations, documents, and a reflexive journal.

In this finding section, I will report three main themes, supported by the professors' perceptions, which emerged in the process of analysis from the composite of the descriptive cases. The emerged themes were that social media sites increased (1) interaction and communication between the instructor and students, (2) interaction, communication, and collaboration among students, (3) and interaction between students with materials.

\section{Social Media Sites Increased Interaction and Communication Between the Instructor and Students}

Many researchers, such as Campbell (2003), Cheon, Song, Jones, and Nam (2011), Ellison and Wu (2008), Sawmiller (2010), Soares (2008), and Yang (2009) have done studies on prominent features of applying social media sites in online teaching and learning activities. They all found that using social media sites in online teaching and learning activities increases interaction and communication between the instructor and students. In fact, social media sites all have a discussion forum, a sending message function, and an instant message chat 
window, so it is very convenient for the instructor and students to interact and communicate with one another during their semester. The professors substantiated the literature:

\section{Prof. Lee Sung:}

Social media sites increase learner communication, interaction, and collaboration. Also, I like to use different types of tools, and I think the students like that kind of trying a new tool. (personal communication)

Prof. Sung taught the course: Mobile Learning in Edmodo. There were twenty six students in his class. In this course, his students had to develop programs. If they had any problems with the assignments or weekly discussions, they had to interact and communicate with the instructor and their peers to complete the tasks. He said:

When students create the mobile apps and they get stuck, I asked someone who did have some problems to send their files and I will modify a little bit and then send the files back to them. So, they use Edmodo the discussion forum, emails, and some other tools too. (personal communication)

\section{Prof. Ken Cook:}

The most prominent feature of social media sites is probably the ability to have a synchronous discussion. (personal communication)

In order to get students involved in the class interaction, Prof. Cook shared ideas that he tried to draw the students into the discussion board. He said that the students naturally wanted to sit back and listen to the teacher rather than to jump in or to contribute. Therefore, Prof. Cook gave them impressions of good approachability where they felt that they could talk. He also emphasized that he had to make sure that nobody in the interaction put the other down and told their peers that the question was stupid. He indicated:

What I do is that I give them opportunities to express their opinions and then I grasp their opinion and move forward. Usually when one is in [one student begins the conversation], they are ok. (personal communication)

Since Prof. Cook used Lync for the class synchronous discussion, his students had three ways to interact with each other in the discussion sessions. The students could interact with the professor and their peers by video-chatting, using microphones, and texting their instant messages via the chat window. The interaction between Prof. Cook and the students and between the students themselves on Lync was very communicative and effective.

Prof. Chris Walker shared some of his ideas about getting advantages of social media sites in communication. He confirmed that social media sites were spaces for the teacher and the students to build their own class community and social communities. Students could get a lot of advantages of social media sites, such as synchronous meetings and asynchronous communication and leaving offline instant messages for their professor and their peers. Prof. Walker said:

Because I have school leaders [in class], so I ask them to share information, post quick bios, but professionally. This is who we are, and then I can start building that community. That's how we [the professor and the students] start to get some safer communication to build community. (personal communication)

Similarly, Prof. Jean Kirk said since the information from the course could be publicly viewed on social media sites, she was very careful about her students' interaction. Prof. Kirk designed ten discussion topics and three writing assignments for the students. Students were encouraged to join social media sites, participate in 
the discussion forums, collect data, report their findings on the class discussion board, and send the report the teacher. She said:

For the assignment, I ask them to formulate a comment that they could post and send to me, but they do not have to actually post it on the site. (personal communication)

Prof. Kirk said that she enjoyed applying social media sites to her online teaching because of its interactive functions. She said:

One of the reasons I use them is because I want the students to see the good ones and so participate in the forum. It keeps students engaged. (personal communication)

\section{Social Media Sites Increased Interaction, Communication, and Collaboration Among the Students Themselves}

The data indicated that the professors chose correct social media sites for their online instructional context. They decided which tools could be used appropriately for their online delivery and which social media sites were good for their students to increase interaction between the professor and the students and among the students themselves to complete their assignments and their experiments. The professors shared their ideas:

Prof. Lee Sung:

In social media, you know the most important function is kind of interaction with each other. When students create the mobile apps, they get stuck. So, some students create some kind of learning groups by themselves so that they can help each other. (personal communication)

He also shared:

The important thing of communication is the immediate response, otherwise, it just looks like emails. So, that means if I post something and I need to wait one or 2 days, that's more like email. But if I use some kind of social media, we [the professor and students] can provide immediate feedback and also the email is only between the students and me. The social media is more like open communication. (personal communication)

Prof. Sung also suggested if anybody in the class knew how to solve a problem, they could post solutions to share and help each other. Prof. Sung shared some of his experiences in increasing students' communication. For example, he asked the students to post two comments to others' postings to make them customize the culture. Once two or three students were active in social media sites, others were not hesitant to communicate or ask questions. Many students posted their answers, their research, and their feedback on the Edmodo discussion board. There were 460 posts during the semester. Prof. Sung said:

I encourage them to respond [to] each other. That means they can learn from each other through communication. (personal communication)

Prof. Sung also emphasized that the teacher had to design some collaborative projects during the semester for students in order to motivate collaboration with their partners. In fact, he designed eleven assignments for the class during the semester. Students had to communicate and collaborate with one another to complete the tasks. He shared his online teaching experiences:

We [instructors] need to design learning activities for students so that they can learn by doing and they can learn by collaboration. (personal communication)

However, Prof. Sung also pointed out that it was not easy to design an effective online course. The teacher 
had to spend more time on designing online module activities. Among the assignments for his class, Prof. Sung designed one of the group projects. It was a case report, so he grouped three or four students together. He gave instructions for the collaborative task. As a group assignment, the students had to set up different kinds of communication tools or social media sites, such as Skype, Second Life, or Go to the meeting to finish the assignment. Social media sites provided students opportunities to meet their homework requirements.

Additionally, Prof. Ken Cook shared:

I let students into my teaching Facebook account, from Physic 1408, a Freshman Physics level class, to get another path to ask for questions. The nice thing with it is that anybody that's using social media sites can get the responses I give or they at least can see the others who are fussy with problems and working towards the answers. That way, they can help one another. (personal communication)

Prof. Cook also emphasized that students were very active and excited using social media sites. If the professor knew how to exploit their involvement and their interests, it was wonderful. He stated:

A lot of young kids have Facebook up on their smart phones or on their computers constantly, and they are interacting every few minutes. (personal communication)

The data indicated that Prof. Cook designed many different learning activities for the students: seven synchronous meetings, four paper assignments, and three videotaped experiments. They had to interact with one another to complete the tasks. The seven synchronous meetings with the whole class via Lync were opportunities for the students to ask the professor questions and to share ideas and answers with their peers. He said:

They are able to talk to one another about how they are understanding of what is physically going on in the medium. They start asking questions. They are able to follow the discussion and when you twist their interest, they are able to follow the pretty convoluted path to understand it. (personal communication)

Since Prof. Cook used Lync for the class synchronous discussion, his students had three ways to interact with each other in the discussion sessions. The students could interact with the professor and their peers by video-chatting, using microphones, and texting their instant messages via the chat window. The interaction between Prof. Cook and the students and between the students themselves on Lync was very communicative and effective.

Observing the online course discussion topics, I realized that many students raised questions. The professor and their peers gave answers and solutions to the problems and experiments. At the end of the semester in May, Prof. Cook also pointed out:

Students comment constantly that they enjoy the interactions. When they want to work collaboratively, they set up their own Facebook pages. They communicate back and forth on that a lot, so they meet each other there and then they have their individual small groups. (personal communication)

Prof. Jean Kirk seemed to be more flexible with her students. She asked her students to look for social media sites that provided information related to her course and her assignments. Students were encouraged to join appropriate social media sites, communicate with people there, and get information. They had to report their findings in the class discussion forum. She said:

They [students] go out and participate or they go out and look at what people are saying. They come back and report 
it to me either in the discussion board or in paper. They have a discussion board each week. I give comments to one or two as part of keeping them engaged. (personal communication)

She has taught online courses with social media sites since 1991 and shared her online teaching experience in using social media sites:

I would never be able to get my students exposed to people who have such radical ideas as I can do on social media sites. I think that's one of the benefits of it [social media site]. Social media sites are good places for students to practice communication skills. (personal communication)

Since students could take advantage of collaborative features from different social media sites to get their homework done, Prof. Chris Walker designed three different collaborative assignments besides four online discussion topics for his students. His purpose for the course was to let students practice leadership communication skills. He set up "Leadership Trios" for his class, so students in the trios had to interact, communicate, and collaborate to complete the class assignments. He set up norms, criteria, and high expectations from the class collaboration. He indicated:

When you share something online, you have to ask yourself: “Do I just say oh that was good?” What does "good” mean? How does it quantify? So the material goes back to that leadership trio. I ask the students to share that with your [student] group. (personal communication)

\section{Social Media Sites Increased Interaction Between the Students and Materials}

One of the good things about social media sites is that it provides space for users to archive materials for their own purposes. The participants in this research got this advantage of social media sites. Before the Spring semester began, they had designed all activities for the course and uploaded related materials for every week or every module to the course. When the course began, the students could interact with the materials to complete their tasks. For example, they can download the materials (e.g., reading articles, Powerpoint files, photos, or videos) for their readings and assignments, they can upload their materials into Edmodo for sharing, and they can submit their tasks in Edmodo.

Here is an example of one module in Edmodo from Prof. Sung's course (see Figure 1).

Besides designing some weekly discussion topic and uploading materials for every week or every module, Prof. Sung designed some collaborative projects during the semester for students in order to motivate collaboration with their partners. In fact, he designed eleven assignments for the class during the semester. Students had to finish the tasks themselves or they could communicate and collaborate with one another to complete the tasks.

Similarly, the data indicated that Prof. Cook designed many different learning activities for the students: seven synchronous meetings, four paper assignments, and three videotaped experiments. They had to interact with the materials and communicate with their peers if necessary to complete the tasks. The seven synchronous meetings with the whole class via Lync were opportunities for the students to ask the professor questions and to share ideas and answers with their peers. 


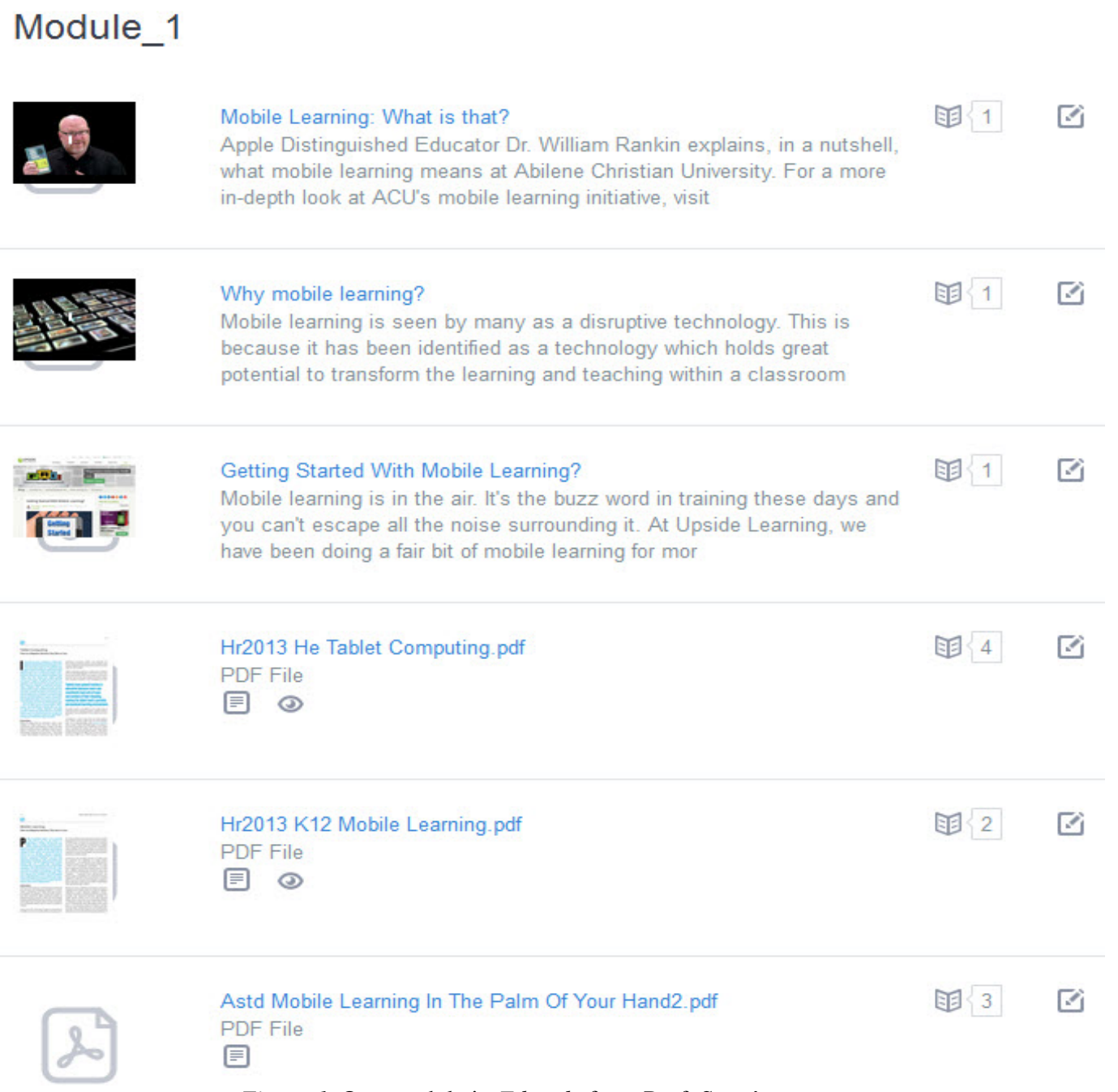

Figure 1. One module in Edmodo from Prof. Sung’s course.

Regarding having students interact with materials during the course, Prof. Kirk designed ten discussion topics and three writing assignments for the students. Students were encouraged to join social media sites, participate in the discussion forums, collect data, report their findings on the class discussion board, and send the report the teacher. Prof. Jean Kirk satisfactorily expressed that social media sites provided her and her students many available and valuable sources of information. I did not find this point from the literature review. For her teaching benefits, she said:

One thing is that so much of the information is already prepared. So if I want the students to have something, I just send them to YouTube videos. They are already done. I do not have to do it. So the convenience is one thing that is tremendously important to me and the quality, you know, young people like you, can put something together that is fascinating. I can take advantage of the creative genius of all these people out there. So, I can bring those to my class. (personal communication)

She also mentioned that social media sites provided a lot of sources for her as a professor and a researcher and for her students as novice researchers. She valued available sources of information on social media sites:

I am grateful that I am living on earth to see the social media sites that are available today. I never thought I would have this much information available to me. I use this to keep my students engaged. (personal communication) 
She also stated that social media sites provided her a just-in-time option for discussing current political events in her policy class. She went on to say when something came up, she sent the students to one or more of the blogs to see what people were saying about the topic. She satisfactorily shared an experience:

This past semester there was a lot happening with Obamacare, so since my students are all nurses, we use these blogs several times a week to see what is being said. (personal communication)

Prof.Kirk also gave another example of social media sites providing her with valuable sources of information. The availability of information on social media sites satisfied her. She said:

I use the APA sites because I teach writing, so I teach APA. There are more APA sites than there used to. And now APA has their own blog, and they have a blog where they answer people's questions about how to use APA. So, it's a good way to help students learn to how to use an interactive blog where they send information and questions, and experts will answer it. (personal communication)

From the data, it indicated that social media sites brought the professors and their students many advantages in online teaching and learning activities. The professors in the study revealed that social media sites increased interaction and communication between the instructor and students; social media sites increased interaction, communication, and collaboration among students; and social media sites increased interaction between students with materials.

\section{Discussion}

The purpose of this study was to examine the professors' perceptions of using social media sites in the online instructional environment. The participants in this study were selected based on the purposive sampling technique of using social media sites in online teaching. The data answered the research question:

What are the perceptions of professors at TTU and other universities concerning their use of social media sites in their course instruction?

The data from the participating professors' interviews, my observations, and collected documents, showed that social media sites had great impact on the online educational environment. The professors all agreed that social media sites could be used to meet their requirements and purposes of online teaching, and social media sites were good tools for their students' learning activities. The prominent features identified by the professors who illustrated their positive views were that social media sites increased interaction and communication between the instructor and students, increased interaction, communication, and collaboration among the students themselves, increased the interaction between students and materials.

Social media sites were the sites by themselves, and they were not useful without the professors' efforts in designing online learning activities for students. Also, students could not finish their assignments without taking advantage of social media sites in the online learning environment. The professors and their students effectively utilized functions of suitable social media sites to interact, to communicate, and to collaborate with one another during the course in their online teaching and learning environments. This finding was consistent with the findings of Campbell (2003), Cheon, Song, Jones, and Nam (2011), Ellison and Wu (2008), and other researchers who found that social media sites promote student-centered learning activities, increase creativity of students during problem solving, enhance interaction between the teacher and students. However, little research has been done on how social media sites increase interaction, communication, and collaboration among the students themselves and how social media sites increase the interaction between students and materials, so the 
findings in the research will contribute to literature.

The data showed that students could work with one another to complete their tasks and assignments. Shy students could join groups with their friendly peers to participate in the class discussion and group work projects. Students could ask the professors for help anytime and anywhere in the case of high importance occurring. These features of social media sites filled the gap: the gap of knowledge, the gap of interactive confidence, and the gap of social communications between the professors and the students and between the students themselves. Social media sites were effective tools, and both the professors and their students could take advantage of social media sites in their teaching and learning activities. The participating professors believed that social media sites could bring benefits to anyone who intends to utilize the prominent features of social media sites in online teaching and learning activities.

\section{Conclusion}

The participating professors used Blogs, Content communities (e.g., YouTube, Skype, Lync, Slideshare) and Social networking sites (e.g., Facebook, EduCreations, Edmodo) in their online teaching in the Spring 2013 semester. The chosen sites were good tools for the professors to fulfill their teaching purposes. The findings of this study were consistent with findings of the previous research about advantages of using social media sites in online teaching and learning activities. The data from the participating professors in this study provided clear and useful ideas about benefits of using social media sites in their online instructional environment. During the data analysis, thematic findings revealed that social media sites increased (1) interaction and communication between the instructor and students, (2) interaction, communication, and collaboration among students, (3) and interaction between students with materials. All of the findings (the themes) in the research supported and answered the research questions: What are the perceptions of professors at TTU and other universities concerning their use of social media sites in their online course instruction? The perceptions of the participating professors from the research confirmed that social media sites could be used effectively in the online instructional environment. The participants were chosen based on purposeful sampling techniques: The participating professors at the university level used social media sites in their online instructional environment. Although the participants came from different departments at different universities, they all revealed that social media sites were good for online instructional environment. It was believed that the findings of this study could be transferred to the similar teaching contexts.

\section{References}

Blackboard, Inc. (n.d). What is blackboard? Retrieved from http://blackboardsupport.calpoly.edu/content/about/whatis.html Bradford, P., Porciello, M., Balkon, N., \& Backus , D. (2007). The blackboard learning system [PDF document]. Retrieved from http://uupinfo.org/research/working/bradford.pdf

Campbell, A. (2003). Weblogs for use with ESL classes. The Internet TESL Journal, 9(2). Retrieved from http://iteslj.org/techniques/campbell-webblogs.html

Chang, V., \& Fisher, D. (2003). The validation and application of a new learning environment instrument for online learning in higher education. In M. Khine\& D. Fisher (Eds.), Technology-rich learning environments: A future perspective (pp. 1-20). Singapore: World Scientific.

Cheon, J., Song, J., Jones, D., \& Nam, K. (2011). Influencing pre-service teachers' intention to adopt Web 2.0 services. Digital Learning in Teacher Education, 27, 53.

Creswell, J. W. (2003). Research design: Qualitative, quantitative, and mixed methods approaches (2nd ed.). Thousand Oaks, CA: Sage.

Denzin, N. K., \& Lincoln, Y. S. (1994). Handbook of qualitative research. Newbury Park: Sage Publications. 
Ellison, N. B., \& Wu, Y. (2008). Blogging in the classroom: A preliminary exploration of student attitudes and impact on Comprehension. Journal of Educational Multimedia \& Hypermedia, 17(1), 99-122.

Emerson, M., Fretz, I., \& Shaw, L. (1995). Writing ethnographic field notes. Chicago: University of Chicago Press.

Erlandson, D., Harris, E., Skipper, B., \& Allen, S. (1993). Doing naturalistic inquiry: A guide to methods. Thousand Oaks, CA: Sage Publications.

Goodyear, P., Salmon, G., Spector, J., Steeples, C., \& Tickner, S. (2001). Competences for online teaching. Educational Technology Research and Development, 49, 65-72.

Hudson Horizons (2012). Features and benefits of social networking websites. Retrieved from http://www.hudsonhorizons.com/Custom-Website-Solutions/Social-Networking/Social-Networking-Features.htm

Kaplan, A., \& Haenlein, M. (2010). Users of the world, unite: The challenges and opportunities of social media. Business Horizons, 53 (1), 59-68.

Lankshear, C. \&Knobel, M. (2006). Blogging as participation: The active sociality of a new literacy. Maidenhead and New York: Open University Press.

Lincoln, Y. S., \& Guba, E. G. (1985). Naturalistic inquiry. Newbury Park, CA: Sage.

Merriam, S. (1988). Qualitative research and case study: Applications in education. San Francisco: Jossey-Bass Publishers.

Patton, M. (2002). Qualitative research and education methods (3rd ed.). Thousand Oaks, CA: Sage.

Pennartz, J. (1989). Semiotic theory and environmental evaluation: A proposal for a new approach and a new method. Symbolic Interaction, 12 (1), 231-249.

Richardson, W. (2010). Blogs, wikis, podcasts, and other powerful web tools for classrooms. California: Cornwin, a SAGE Company.

Rossman, G., \& Rallis, S. (2003). Learning in the field: An introduction to qualitative research. Thousand Oaks, CA: Sage.

Sawmiller, A. (2010). Classroom blogging: What is the role in science learning?. Clearing House, 83(2), 44-48.

Sifry, D. (2007). The state of the live web. Retrieved from http://www.sifry.com/alerts/archives/000493.html

Soares, D. (2008). Understanding class blogs as a tool for language development. Language Teaching Research, 12(4), $517-533$.

Strauss, A., \& Corbin, J. (1990). Basics of qualitative research: Grounded theory procedures and techniques. Newbury Park, CA: Sage

Sylvester, T. (2011). Hoover's company profiles: Blackboard Inc. Retrieved from http://www.answers.com/topic/blackboard-inc

Ventureneer (2011). Social media for your nonprofit: Take charge! [PDF document]. Retrieved from http://ventureneer.com/sites/default/files/ebooks/ventureneer-socialmedia-nonprofits-take-charge.pdf

Wang, Y. (2006). Technology projects as a vehicle to empower students. Educational Media International, 43(4), 315-330.

Yang, S. (2009). Using blogs to enhance critical reflection and community of practice [PDF document]. Journal of Educational Technology \& Society, 12(2), 11-21. Retrieved fromhttp://www.ifets.info/journals/12_2/2.pdf

Yin, R. K. (1984). Case study research: Design and methods. Thousand Oaks, CA: Sage. 